\title{
Evaluation of Impact Strength and Surface Hardness of Acrylic Resin Modified with Different Nano Materials: An In Vitro Study
}

\author{
Kanesha Abrol $^{1}$, Samarth K Agarwal ${ }^{2}$, Rachna Maheshwari ${ }^{3}$, Romil Singhal ${ }^{4}$, Swatantra Agarwal ${ }^{5}$
}

\begin{abstract}
Aim: The fracture of the denture resulting from the accidental fall on the ground is affected by the impact strength of the acrylic resin. Many attempts have been made to improve the mechanical properties of acrylic resin by reinforcing it with different materials. The aim of this study was to evaluate the effect of addition of different nano materials on the impact strength and surface hardness of the acrylic resin.

Materials and methods: Fifty samples of dimensions $65 \mathrm{~mm} \times 10 \mathrm{~mm} \times 3 \mathrm{~mm}$ were made and divided into five groups. Group I is the control group of heat-activated polymethyl methacrylate (PMMA) acrylic resin, while groups II, III, IV, and V are having $1 \%$ and $3 \%$ zirconium oxide $\left(\mathrm{ZrO}_{2}\right)$ and silicon dioxide $\left(\mathrm{SiO}_{2}\right)$ nanoparticles in heat-activated PMMA by weight, respectively. A metallic block was fabricated and invested into addition silicone impression material to form a mold. The modeling wax was melted and flown into the mold cavity to form the wax block. The samples were subsequently polymerized, retrieved, finished, and polished. Impact strength and surface hardness were measured by Izod impact testing machine and Vickers hardness tester, respectively.

Results: The results showed that the control group had the highest impact strength and lowest value was observed with $1 \% \mathrm{SiO}_{2}$. The value of Vickers hardness was maximum with $1 \% \mathrm{ZrO}_{2}$ and least with the control group. The analysis of variance (ANOVA) for both the impact strength and surface hardness indicated a $p$ value of $<0.001$, which is very highly significant.

Conclusion: Incorporation of $\mathrm{ZrO}_{2}$ and $\mathrm{SiO}_{2}$ nanoparticles into the heat-activated PMMA affects the impact strength and surface hardness. Keywords: Acrylic resin, Impact strength, Nanoparticles, Silicon dioxide, Surface hardness, Zirconium oxide. International Journal of Prosthodontics and Restorative Dentistry (2019): 10.5005/jp-journals-10019-1254
\end{abstract}

\section{INTRODUCTION}

Polymethyl methacrylate (PMMA), a derivative of acrylic acid and most commonly referred as acrylic resin, was introduced as the widely used denture base material in 1937 by Walter Wright. Since then it became the most reliable material for denture construction. ${ }^{1-3}$ Despite its favorable properties such as satisfying esthetics, ease of processing, and acceptable cost, it is not considered an ideal material due to its inferior properties such as surface hardness and low impact strength. ${ }^{4,5}$ Impact failures that happen as a result of accidental dropping of the denture lead to crack propagation which affects its clinical performance. ${ }^{1-13}$ Another crucial property is surface hardness which relates to the material wear that can take place during daily denture brushing causing roughness and facilitating microbial adhesion. ${ }^{6,7}$ Several techniques have been investigated to improve the properties of PMMA by incorporating suitable fillers such as fibers, metal oxides, or rubber like substances in its composition. ${ }^{8}$ The recent approach was to improve the properties by addition of $\mathrm{ZrO}_{2}$ and $\mathrm{SiO}_{2}$ nanoparticles as filler. Not only because of its biocompatibility and superior esthetics, these nano fillers are also characterized by their small size, large surface area, active function, and strong interfacial interaction with the organic polymer. ${ }^{9}$ Therefore, the purpose of the present study is to evaluate the impact strength and the surface hardness of heat-activated PMMA after addition of different concentrations of $\mathrm{ZrO}_{2}$ and $\mathrm{SiO}_{2}$ nanoparticles in it.

\section{Materials and Methods}

This in vitro study was conducted in the Department of Prosthodontics and Crown and Bridge, Kothiwal Dental College
${ }^{1-5}$ Department of Prosthodontics and Crown and Bridge, Kothiwal
Dental College and Research Centre, Moradabad, Uttar Pradesh, India
Corresponding Author: Kanesha Abrol, Department of Prosthodontics
and Crown and Bridge, Kothiwal Dental College and Research Centre,
Moradabad, Uttar Pradesh, India, Phone: +919906069379 , e-mail:
drkaneshaabrol92@gmail.com
How to cite this article: Abrol K, Agarwal SK, Maheshwari R, et al.
Evaluation of Impact Strength and Surface Hardness of Acrylic
Resin Modified with Different Nano Materials: An In Vitro Study. Int J Prosthodont Restor Dent 2019;9(4):113-116.

Source of support: Nil

Conflict of interest: None

and Research Centre, Moradabad. A conventional heat-cure denture base resin (Trevalon; Dentsply India Pvt Ltd) was used as a matrix component; and $\mathrm{ZrO}_{2}$ and $\mathrm{SiO}_{2}$ nanoparticles (Nano Research Lab, Jamshedpur, Jharkhand, India) were used as a reinforcing agent.

In this study, a rectangular metallic model of dimension $65 \mathrm{~mm} \times 10 \mathrm{~mm} \times 3 \mathrm{~mm}$ (ADA specification no. 12) was invested into addition silicone impression material (Flexceed; GC India Dental Pvt Ltd) to form a mold. Modeling wax (DPI; Dental Products of India, Mumbai, Maharashtra, India) was melted and flown into the mold to form the wax patterns. A total of 50 specimens were fabricated for this study, and they were divided into 5 groups and each group consisted of 10 specimens as follows:

- Group I-heat cure denture base acrylic resin as control group,

- Group II-heat cure denture base acrylic resin containing 1 wt\% $\mathrm{ZrO}_{2}$,

(c) The Author(s). 2019 Open Access This article is distributed under the terms of the Creative Commons Attribution 4.0 International License (https://creativecommons. org/licenses/by-nc/4.0/), which permits unrestricted use, distribution, and non-commercial reproduction in any medium, provided you give appropriate credit to the original author(s) and the source, provide a link to the Creative Commons license, and indicate if changes were made. The Creative Commons Public Domain Dedication waiver (http://creativecommons.org/publicdomain/zero/1.0/) applies to the data made available in this article, unless otherwise stated. 
- Group III-heat cure denture base acrylic resin containing 3 wt $\% \mathrm{ZrO}_{2}$,

- Group IV-heat cure denture base acrylic resin containing $1 \mathrm{wt} \% \mathrm{SiO}_{2}$,

- Group $\mathrm{V}$-heat cure denture base acrylic resin containing $3 \mathrm{wt} \% \mathrm{SiO}_{2}$.

The wax patterns were invested into type III dental stone (Kalstone; Kalabhai Karson Pvt Ltd, Mumbai, Maharashtra, India) in the lower half of the flask. Upon reaching its initial set, the stone was coated with cold mold seal (Dental Products of India, Mumbai, Maharashtra, India) and the upper portion of the flask was then placed atop its lower portion. Upon completion of the setting process, the flask was immersed in boiling water and conventional dewaxing procedures were carried out. The mold spaces were cleaned of any wax traces by immersion in hot water and then allowed to dry. The $\mathrm{ZrO}_{2}$ and $\mathrm{SiO}_{2}$ nanoparticles were weighed using an electronic balance and added in the concentration of $1 \%$ and $3 \%$ each to the heat cure acrylic resin polymer (Dentsply India Pvt Ltd) for the subsequent groups. The particles were thoroughly mixed and stirred to achieve an equal distribution within the polymer. The modified acrylic powder and monomer were mixed in a ratio of 3:1 and then packed in a dough stage into the mold cavity. Trial closure was done until the flash was no longer apparent followed by definitive closure and the flask was left for 60 minutes for bench curing before processing for the curing cycle. The processing was carried out in the water bath at $74^{\circ} \mathrm{C}$ for approximately 2 hours and increasing the temperature of the water bath to $100^{\circ} \mathrm{C}$ and processing for 1 hour. Following the completion of polymerization cycle, the flasks were bench cooled to room temperature. The samples were retrieved and finished with a tungsten carbide bur and abrasive paper. Final polishing was accomplished with pumice and a cotton cloth wheel on the polishing lathe (Fig. 1). All the specimens were stored in distilled water at $37^{\circ} \mathrm{C}$ for 24 hours before testing.

The impact strength test was performed by using the IZOD pendulum impact testing machine (Model: 6545/000; Ceast, Italy). The specimens were clamped at one end vertically in a metal fixture, and the notched surface of the specimens facing the striking pendulum was used to break the specimens. The impact strength of a specimen was recorded as the number of joules of energy absorbed in breaking the specimen. The surface hardness was measured by using the Digital Vickers Micro hardness tester
(Fischerscope HM 2000). A $30 \mathrm{gf}$ load was applied by the diamond pyramid for 20 seconds indentation time and Vickers hardness number (VHN) was obtained digitally. The mean impact strength and surface hardness for each group were calculated. The data were tabulated and statistically analysis.

\section{RESULTS}

The highest mean impact strength was seen in group I (control group) $-20.72 \mathrm{~kJ} / \mathrm{m}^{2}$ (standard deviation, $\mathrm{SD}=0.483$ ) compared to the subsequent groups containing $\mathrm{ZrO}_{2}$ (groups II and III) and $\mathrm{SiO}_{2}$ nanoparticles (groups IV and $\mathrm{V}$ ). The least value was for group IV $\left(1 \% \mathrm{SiO}_{2}\right)=17.84 \mathrm{~kJ} / \mathrm{m}^{2}$ as depicted in Table 1 . Table 2 depicts the highest mean Vickers hardness of group II ( $\left.1 \% \mathrm{ZrO}_{2}\right)-14.74 \mathrm{HV}$ $(\mathrm{SD}=0.450)$ compared to group I (control group) $=13.22 \mathrm{HV}(\mathrm{SD}=$ 0.835 ) which indicated the lowest value among all the groups.

One-way ANOVA for impact strength and surface hardness indicated statistically significant differences between the conventional heat cure resin and modified heat cure resin with incorporation of nanoparticles as $p$ value is $<0.001$.

The intergroup comparison based on impact strength among the various groups (Table 3 ) indicated very highly statistically significant results ( $p$ value $<0.001)$ except when group II $(1 \%$ $\left.\mathrm{ZrO}_{2}\right)$ was compared with group IV $\left(1 \% \mathrm{SiO}_{2}\right)$. In Table 4 , the results of intergroup comparison based on Vickers hardness show no significant differences between the following groups: I vs III, II vs IV, III vs V, and IV vs V.

\section{Discussion}

In the present study, the mechanical properties, in particular the impact strength and surface hardness, of PMMA were evaluated after the incorporation of $\mathrm{ZrO}_{2}$ and silica dioxide nanoparticles in two different percentages, respectively.

The results of the impact strength revealed a highly significant difference between the control group and the modified test groups. The highest mean value was seen in group I [control group $=(20.72$ $\pm 0.483)]$, while group IV $\left[1 \% \mathrm{SiO}_{2}=(17.84 \pm 0.430)\right]$ revealed the minimum impact strength. The significant decrease in impact strength (as compared to the control) with increase in the ratio of reinforcement may be due to the agglomeration of nanoparticles, which resulted in loosely bounded cluster formations where crack

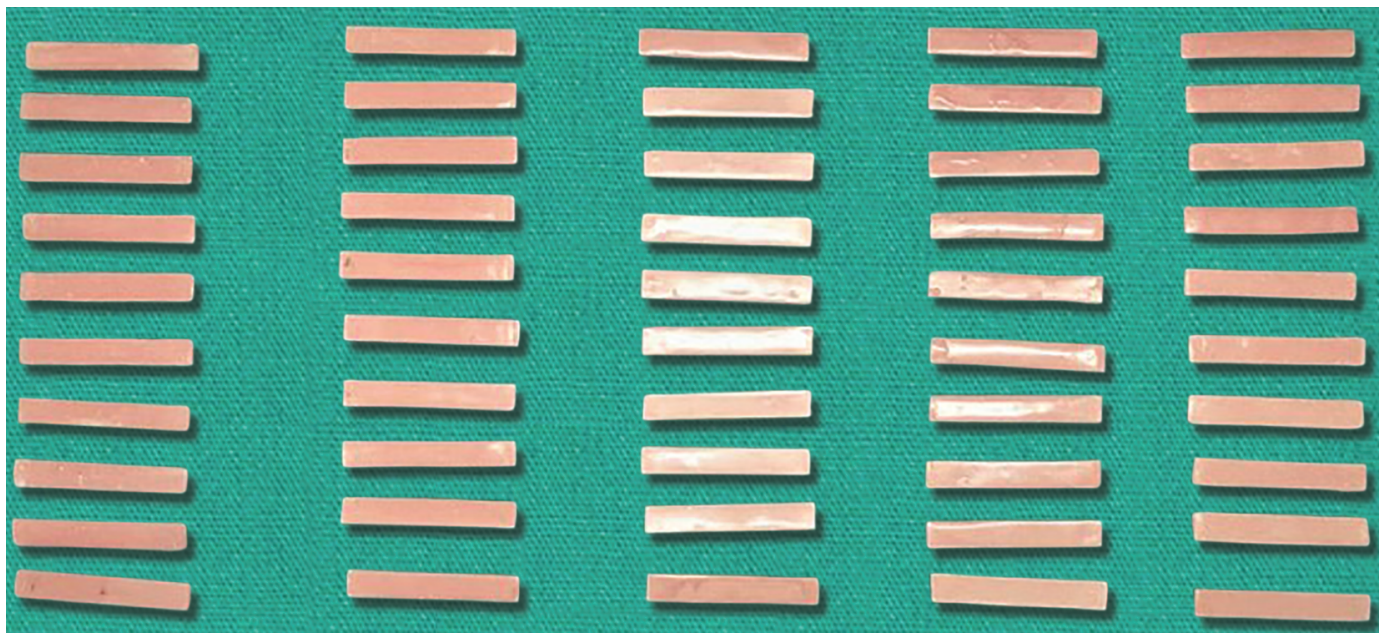

Fig. 1: Finished and polished acrylic samples 
Table 1: Descriptive statistics of impact strength among various groups

\begin{tabular}{llllllll}
\hline & & & & \multicolumn{2}{c}{ 95\% confidence interval for mean } & \\
\cline { 5 - 6 } Impact strength & $n$ & Mean & $S D$ & Lower bound & Upper bound & Min. & Max. \\
\hline Group I (control group) & 10 & 20.72 & 0.483 & 20.37 & 21.07 & 18.30 & 20 \\
Group II $\left(1 \% \mathrm{ZrO}_{2}\right)$ & 10 & 18.01 & 0.409 & 17.72 & 19.94 & 17 & 19 \\
Group III $\left(3 \% \mathrm{ZrO}_{2}\right)$ & 10 & 19.66 & 0.398 & 19.38 & 18.15 & 19 & 20 \\
Group IV $\left(1 \% \mathrm{SiO}_{2}\right)$ & 10 & 17.84 & 0.430 & 17.53 & 18.95 & 17 & 19 \\
Group V $\left(3 \% \mathrm{SiO}_{2}\right)$ & 10 & 18.73 & 0.313 & 18.51 & &
\end{tabular}

Table 2: Descriptive statistics of Vickers hardness among various groups

\begin{tabular}{llllllll}
\hline & & & & \multicolumn{3}{c}{ 95\% confidence interval for mean } & \\
\cline { 5 - 6 } Vickers hardness & $n$ & Mean & $S D$ & Lower bound & Upper bound & Min. & Max. \\
\hline Group I (control group) & 10 & 13.22 & 0.835 & 12.62 & 13.82 & 12 & 14 \\
Group II $\left(1 \% \mathrm{ZrO}_{2}\right)$ & 10 & 14.74 & 0.450 & 14.42 & 15.06 & 14 & 15 \\
Group III $\left(3 \% \mathrm{ZrO}_{2}\right)$ & 10 & 13.75 & 0.699 & 13.25 & 14.25 & 12 & 15 \\
Group IV $\left(1 \% \mathrm{SiO}_{2}\right)$ & 10 & 14.67 & 0.482 & 14.32 & 14.54 & 14 & 15 \\
Group V $\left(3 \% \mathrm{SiO}_{2}\right)$ & 10 & 14.15 & 0.536 & 13.77 & & 13 \\
\hline
\end{tabular}

Table 3: Intergroup comparison based on impact strength among various groups

\begin{tabular}{lcccc}
\hline & & & \multicolumn{2}{c}{$95 \%$ confidence interval } \\
\cline { 3 - 5 } Group comparison & Mean difference & $p$ value & Lower bound & Upper bound \\
\hline I (control) vs II $\left(1 \% \mathrm{ZrO}_{2}\right)$ & 2.71 & $<0.001^{*}$ & 2.34 & 3.08 \\
I (control) vs III $\left(3 \% \mathrm{ZrO}_{2}\right)$ & 1.06 & $<0.001^{*}$ & 0.69 & 1.43 \\
I (control) vs IV $\left(1 \% \mathrm{SiO}_{2}\right)$ & 2.88 & $<0.001^{*}$ & 2.51 & 3.25 \\
I (control) vs V $\left(3 \% \mathrm{SiO}_{2}\right)$ & 1.99 & $<0.001^{*}$ & 1.62 & 2.36 \\
II $\left(1 \% \mathrm{ZrO}_{2}\right)$ vs III $\left(3 \% \mathrm{ZrO}_{2}\right)$ & -1.65 & $<0.001^{*}$ & -2.02 & -1.28 \\
II $\left(1 \% \mathrm{ZrO}_{2}\right)$ vs IV $\left(1 \% \mathrm{SiO}_{2}\right)$ & 0.17 & 0.359 & -0.20 & 0.54 \\
II $\left(1 \% \mathrm{ZrO}_{2}\right)$ vs V $\left(3 \% \mathrm{SiO}_{2}\right)$ & -0.72 & $<0.001^{*}$ & -1.09 & -0.35 \\
III $\left(3 \% \mathrm{ZrO}_{2}\right)$ vs IV $\left(1 \% \mathrm{SiO}_{2}\right)$ & 1.82 & $<0.001^{*}$ & 1.45 & 2.19 \\
III $\left(3 \% \mathrm{ZrO}_{2}\right)$ vs V $\left(3 \% \mathrm{SiO}_{2}\right)$ & 0.93 & $<0.001^{*}$ & 0.56 & 1.30 \\
IV $\left(1 \% \mathrm{SiO}_{2}\right)$ vs V $\left(3 \% \mathrm{SiO}_{2}\right)$ & -0.89 & $<0.001^{*}$ & -1.26 & -0.52 \\
\hline
\end{tabular}

Table 4: Intergroup comparison based on Vickers hardness among various groups

\begin{tabular}{llcrc}
\hline & & & \multicolumn{2}{c}{$95 \%$ confidence interval } \\
\cline { 3 - 5 } Group comparison & Mean difference & $p$ value & Lower bound & Upper bound \\
\hline I (control) vs II $\left(1 \% \mathrm{ZrO}_{2}\right)$ & -1.52 & $<0.001^{*}$ & -2.08 & -0.96 \\
I (control) vs III $\left(3 \% \mathrm{ZrO}_{2}\right)$ & -0.53 & 0.061 & -1.09 & 0.03 \\
I (control) vs IV $\left(1 \% \mathrm{SiO}_{2}\right)$ & -1.45 & $<0.001^{*}$ & -2.00 & -0.89 \\
I (control) vs V $\left(3 \% \mathrm{SiO}_{2}\right)$ & -0.93 & $0.002^{*}$ & -1.49 & -0.38 \\
II $\left(1 \% \mathrm{ZrO}_{2}\right)$ vs III $\left(3 \% \mathrm{ZrO}_{2}\right)$ & 0.99 & $0.001^{*}$ & 0.43 & 1.55 \\
II $\left(1 \% \mathrm{ZrO}_{2}\right)$ vs IV $\left(1 \% \mathrm{SiO}_{2}\right)$ & 0.07 & 0.790 & -0.48 & 0.63 \\
II $\left(1 \% \mathrm{ZrO}_{2}\right)$ vs V $\left(3 \% \mathrm{SiO}_{2}\right)$ & 0.59 & $0.039^{*}$ & 0.03 & 1.14 \\
III $\left(3 \% \mathrm{ZrO}_{2}\right)$ vs IV $\left(1 \% \mathrm{SiO}_{2}\right)$ & -0.92 & $0.002^{*}$ & -1.47 & -0.36 \\
III $\left(3 \% \mathrm{ZrO}_{2}\right)$ vs V $\left(3 \% \mathrm{SiO}_{2}\right)$ & -0.40 & 0.153 & -0.96 & 0.15 \\
IV $\left(1 \% \mathrm{SiO}_{2}\right)$ vs V $\left(3 \% \mathrm{SiO}_{2}\right)$ & 0.51 & 0.070 & -0.04 & 1.07 \\
\hline
\end{tabular}

formation may occur and affect the impact strength. ${ }^{3,8}$ It has been reported that the increasing weight percentage of nano- $\mathrm{ZrO}_{2}$ powder affects the interface region due to poor adhesion between the untreated filler particles and matrix which lead to the lowering of energy dissipation per unit volume and consequently decrease in the impact strength. ${ }^{10}$ These findings are in agreement with the studies done by Gad et al., ${ }^{3}$ Alhavaz et al., ${ }^{10}$ and Asopa et al. ${ }^{8}$
A nonsignificant result ( $p$ value of 0.359 ) was seen in the impact strength when group II ( $\left.1 \% \mathrm{ZrO}_{2}\right)$ was compared with group IV $\left(1 \% \mathrm{SiO}_{2}\right)$. This is because only the correct concentration of the nanoparticles can be clinically acceptable and significant values of mechanical properties be obtained. Very small percentage of nanozirconia and nano-silica does not produce a statistically significant result as quoted by lhab et al. ${ }^{9}$ and Cevik et al. ${ }^{5}$ 
The results of hardness showed an increase in the mean values with increase in the amount of filler. Highly significant differences were seen between the control and the nano filler groups. The maximum value for surface hardness was seen in group II [1\% $\left.\mathrm{ZrO}_{2}=(14.74 \pm 0.450)\right]$, and the least value was for group I [control group $=(13.22 \pm 0.835)]$. The increase in the surface hardness by adding these nanoparticles may be attributed to their strong ionic interatomic bonding into the resin matrix. ${ }^{10}$ However, as the concentration of the nanoparticle increases, it leads to the poor adhesion to the resin matrix with the emergence of clusters that act as a defect in the resin structure. ${ }^{12}$ On comparison of group I (control group) with group III ( $\left.3 \% \mathrm{ZrO}_{2}\right)$, a nonsignificant result was obtained with a $p$ value of $>0.05$. It may be due to the increased inorganic filler per unit area which gives more resistance to the penetration of the Vickers indenter. The result was also in accordance with Alhavaz et al. ${ }^{10} \mathrm{~A}$ nonsignificant result was obtained on comparison of group IV $\left(1 \% \mathrm{SiO}_{2}\right)$ and group V $\left(3 \% \mathrm{SiO}_{2}\right)$ which could be due to the weak nature of coupling between nano-silica and the polymer matrix at a higher concentration.

A comparative evaluation between the above-mentioned results with other studies could not be agreed upon due to the differences in regard to the type of nano filler particle used in the present study. Therefore, further studies on a larger sample size with different types of denture base material using various concentrations of the nano filler and its surface modification are recommended. In addition, clinical studies should be proposed to investigate the clinical performance of such nanoparticles inside the oral cavity.

\section{Conclusion}

Based on the results obtained in the present study, the following conclusions were drawn:

- Highest impact strength was observed in heat-activated PMMA, (control group) and lowest in the $1 \% \mathrm{SiO}_{2}$ group.

- Incorporation of $1 \% \mathrm{ZrO}_{2}$ in PMMA increased the surface hardness to remarkable values and it was found to be least in the control group.

- Reinforcement of heat-activated PMMA with nanoparticles tested affects both the impact strength and surface hardness of the acrylic resin significantly.

- Effect of incorporation of $\mathrm{ZrO}_{2}$ and $\mathrm{SiO}_{2}$ on impact strength and surface hardness depends on the concentration of the nanoparticle used.

\section{References}

1. Sabarigirinathan $C$, Vinayagavel $K$, Rupkumar $P$, et al. A comparative study to evaluate the mechanical properties of zirconium oxide added polymethyl methacrylate by two different methods at two different concentrations. Ann Int Med Dent Res 2015;1(3):161-165.

2. Choksi RH, Mody PV. Flexural properties and impact strength of denture base. J Indian Prosthodont Soc 2016;16(3):264-270. DOI: 10.4103/0972-4052.176532.

3. Gad MM, Rahoma A, Thobity AM, et al. Influence of incorporation of $\mathrm{ZrO}_{2}$ nanoparticles on the repair strength of polymethyl methacrylate denture bases. Int J Nanomedicine 2016;11:5633-5643. DOI: 10.2147/ IJN.S120054.

4. Ahmed MA, El-Shennawy M, Althomali YM, et al. Effect of titanium dioxide nano particles incorporation on mechanical and physical properties on two different types of acrylic resin denture base. World J Nano Sci Eng 2016;6:111-119. DOI: 10.4236/wjnse.2016.63011.

5. Cevik P, Yildirim-Bicer AZ. The effect of silica and prepolymer nanoparticles on the mechanical properties of denture base acrylic resins. J Prosthodont 2018;27(8):763-770. DOI: 10.1111/jopr.12573.

6. Safarabadi M, Khansari NM, Rezaei A. An experimental investigation of $\mathrm{HA} / \mathrm{AL}_{2} \mathrm{O}_{3}$ nanoparticles on mechanical properties of restorative materials. Eng Solid Mech 2014;2(3):173-182. DOI: 10.5267/ j.esm.2014.4.006.

7. Dikbas I, Gurbuz O, Unalan F, et al. Impact strength of denture polymethyl methacrylate reinforced with different forms of E-glass fibres. Acta Odontol Scand 2013;71(3-4):727-732. DOI: 10.3109/00016357.2012.715198.

8. Asopa V, Suresh S, Khandelwal M, et al. A comparative evaluation of properties of zirconia reinforced high impact acrylic resin with that of high impact acrylic resin. Saudi J Dent Res 2015;6(2):145-151. DOI: 10.1016/j.sjdr.2015.02.003.

9. Ihab NS, Moudhaffar M. Evaluation of effect of modified nano-fillers addition on some properties of heat cured acrylic denture base material. J Bagh Coll Dent 2011;23(3):23-29.

10. Alhavaz A, Dastjerdi MR, Ghasemi A, et al. Effect of untreated zirconium oxide nanofiller on the flexural strength and surface hardness of autopolymerized interim fixed restorations resins. J Esthet Restor Dent 2017;29(4):264-269. DOI: 10.1111/jerd.12300.

11. McNally LM, Sullivan DJ, Jagger DC. An in vitro investigation of the effect of the addition of untreated and surface treated silica on the transverse and impact strength of polymethyl methacrylate acrylic resin. Biomed Mater Eng 2006;16(2):93-100.

12. Zhang X, Zhang X, Huang Z, et al. Hybrid effects of zirconia nanoparticles with aluminium borate whiskers on mechanical properties of denture base resin PMMA. Dent Mater J 2014;33(1): 141-146. DOI: 10.4012/dmj.2013-054.

13. Jagger $\mathrm{DC}$, Harrison $\mathrm{A}$, Jandt KD. The reinforcement of dentures. J Oral Rehabil 1999;26(3):185-194. DOI: 10.1046/j.1365-2842.1999.00375.x. 